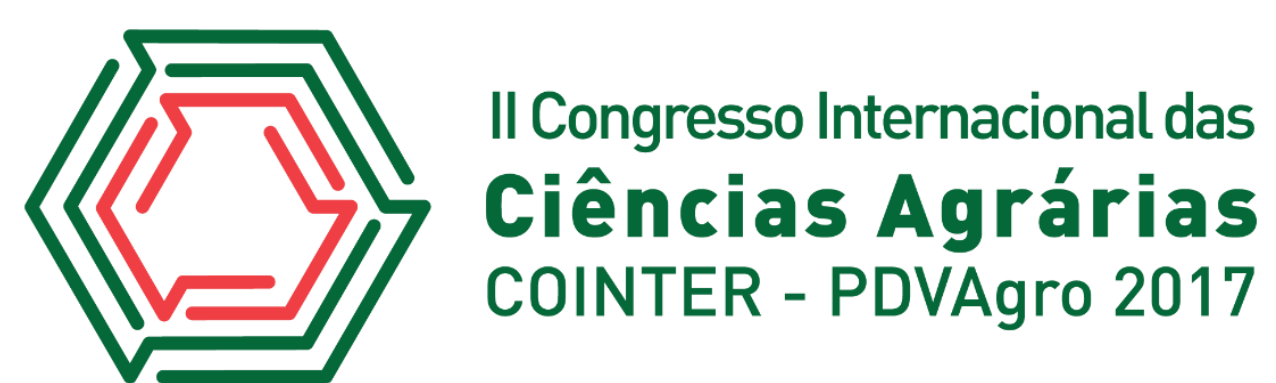

\title{
AMIDO, AÇÚCARES REDUTORES E NÃO REDUTORES, SACAROSE E GLICINA- BETAÍNA EM PLANTAS JOVENS DE PARICÁ ACOMETIDAS À DOSAGENS DE ALUMÍNIO
}

\begin{abstract}
Ana Ecídia de Araújo Brito ${ }^{1}$; Vitor Resende do Nascimento ${ }^{2}$; Kerolém Prícila Sousa Cardoso $^{3}$; Glauco André dos Santos Nogueira ${ }^{4}$; Cândido Ferreira de Oliveira Neto ${ }^{5}$
\end{abstract}

\section{Introdução}

O paricá (Schizolobium amazonicum Huber ex Ducke) apresenta rápido crescimento e madeira com elevada cotação no mercado interno e externo, e por isso vem sendo bastante cultivado pelas empresas madeireiras das regiões Norte e Nordeste do Brasil, sendo uma madeira muito cobiçada para a produção de compensados, e considerada a melhor espécie para a fabricação de MDF (ROSA, 2011).

Os solos amazônicos são altamente intemperizados e caracterizados por acidez elevada, alta saturação por alumínio e baixa concentração de nutrientes, em função das elevadas taxas de lixiviação. Estudos têm mostrado que $\mathrm{o} \mathrm{Al}^{+3}$ prejudica o crescimento e o desenvolvimento de plantas sensíveis, como também mostrado a existência de plantas resistentes e/ou tolerantes (DELHAIZE et al., 2012).

Assim, o trabalho teve o objetivo de avaliar os teores de amido, açúcares redutores e não redutores e sacarose em plantas jovens de paricá (Schizolobium amazonicum (Huber ex Ducke) acometidas à diferentes dosagens de alumínio. Tendo como hipótese que as dosagens de alumínio irão afetar negativamente as variáveis estudadas.

\section{Fundamentação teórica}

$\mathrm{O} \mathrm{Al}^{+3}$ pode causar efeitos drásticos na assimilação de $\mathrm{N}$ em plantas (PAL'OVEBALANG;MISTRIK, 2011). Segundo Sharma \& Dubey (2005), um dos mecanismos fisiológicos de resposta das plantas aos diversos estresses é o ajustamento osmótico, em que ocorre a biossíntese e acúmulo de solutos compatíveis como a prolina e a glicina-betaína (função osmoprotetora).

\footnotetext{
${ }^{1}$ Pós-graduação em Agronomia, Universidade Federal Rural da Amazônia, ecidiabrito@ hotmail.com

${ }^{2}$ Pós-graduação em Ciências Florestais, Universidade Federal Rural da Amazônia, vitoresf@gmail.com

${ }^{3}$ Pós-graduação em Ciências Florestais, Universidade Federal Rural da Amazônia, k.cardoso.agro@gmail.com

${ }^{4}$ Pós-graduação em Ciências Florestais, Universidade Federal Rural da Amazônia, glauand@ yahoo.com.br

${ }^{5}$ Professor doutor, Universidade Federal Rural da Amazônia, candido.neto@ufra.edu.br
} 


\section{Metodologia}

O experimento foi conduzido em casa de vegetação pertencente à UFRA-Universidade Federal Rural da Amazônia, Belém, Pará, no período de abril á julho de 2016. Delineamento do tipo DIC, sendo 6 tratamentos (Controle, Al 15 mg/L, Al 30 mg/L, Al 45 mg/L, Al 60 mg/L e Al 75 $\mathrm{mg} / \mathrm{L}$ ) com 5 repetições cada (uma planta/vaso), totalizando 30 unidades experimentais.. O alumínio foi aplicado na forma de $\left(\mathrm{AlCl}_{3} \cdot 6 \mathrm{H}_{2} 0\right) 95 \%$, e o pH da solução foi mantido em 4,8. Foi feita análise estatística dos dados, utilizando-se análise de variância, análise de regressão (análise quantitativa) e teste de Tukey 5\%. Foram determinados os teores de Amido (HODGE \& HOFREITER, 1962); Açúcares redutores e não redutores (RINNER et al., 2012); Sacarose (VAN HANDEL et al, 1968); Glicina-betaína (GRIEVE \& GRATTAN, 1983).

\section{Resultados e Discussões}

A concentração de amido nas folhas (Figura 1A) apresentou comportamento descrescente, enquanto as raízes (Figura 1B) apresentaram leve redução de amido na dosagem de $15 \mathrm{mg} \mathrm{L}^{-1}$. A diminuição de amido nas folhas (Figura 1A) ocorre em detrimento da diminuição da atividade fotossintética em um aumento da degradação do amido pelas enzimas $\alpha$ e $\beta$ amilase, formando novos açúcares. Já para a raiz, a redução segundo Pimentel (2004) está relacionada à diminuição do fluxo de fotoassimilados da folha para a raiz, devido ao fato do estresse vegetal promover uma redução no potencial de pressão positiva do floema.

Figura 1. Concentrações de Amido (A - folhas; B - raízes em plantas jovens de Schizolobium amazonicum Huber ex

Ducke acometidas à dosagens de $\mathrm{AlCl}_{3}$.
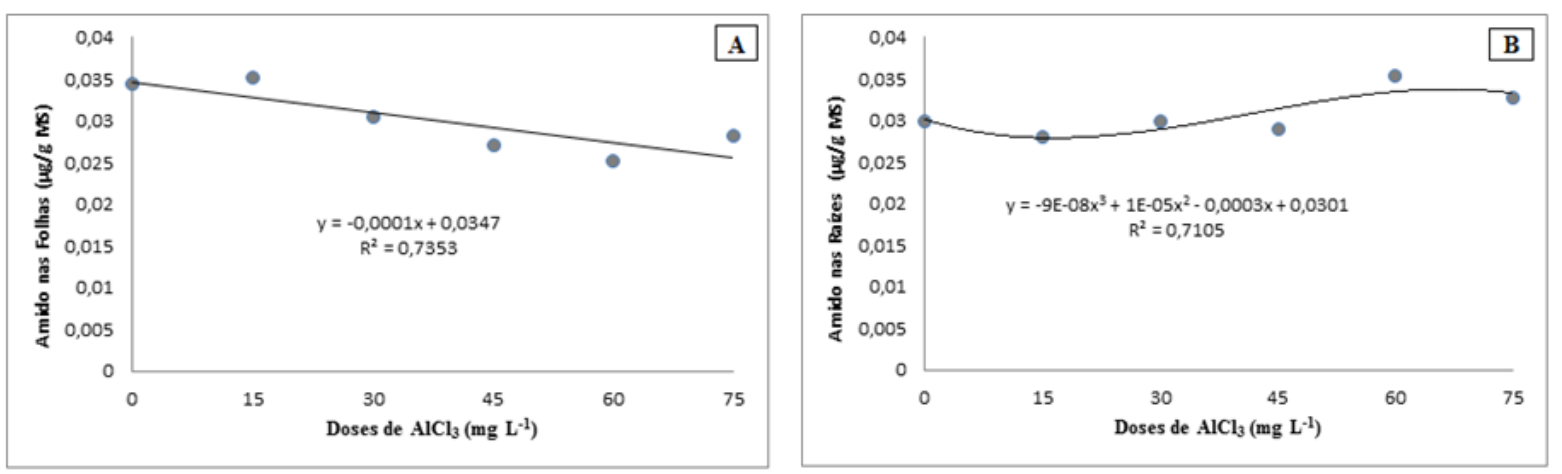

Açúcares redutores apresentaram valores de 0.02 (plantas controle nas folhas) e $0.01 \mu \mathrm{mol} \mathrm{\textrm {g } ^ { - }}$ ${ }^{1} \mathrm{MS}$ (75 $\mathrm{mg} \mathrm{L}^{-1}$ nas folhas), e valores de 0.016 (plantas controle nas raízes) e $0.009 \mu \mathrm{mol} \mathrm{g}^{-1} \mathrm{MS}$ (75 $\mathrm{mg} \mathrm{L}^{-1}$ nas raízes), respectivamente figuras $2 \mathrm{~A}$ e $2 \mathrm{~B}$. A concentração de açúcares não redutores 
apresentou tendência de crescimento nas folhas até a dosagem de $30 \mathrm{mg} \mathrm{L}^{-1}$, variando de 48.2 $\mathrm{mg} / \mathrm{dL}$ (dosagem de $30 \mathrm{mg} \mathrm{L}^{-1}$ ) a $31.6 \mathrm{mg} / \mathrm{dL}$ (dosagem de $75 \mathrm{mg} \mathrm{L}^{-1}$ ), um decréscimo de $34.44 \%$ (Figura 2C). Teores de açúcares não redutores nas raízes com valores de 0.24 e $0.18 \mathrm{mg} / \mathrm{dL}$ nos tratamentos controle (0) e $75 \mathrm{mg} \mathrm{L}^{-1}$ respectivamente (Figuras $2 \mathrm{C}$ e $2 \mathrm{D}$ ).

Segundo Jones (1998), as raízes passam a aumentar a produção de exsudatos (ácidos orgânicos, açúcares, aminoácidos, fenólicos) em quantidade diretamente proporcional à atividade externa de alumínio.

Figura 2. Concentrações de Açúcares redutores (A - folhas; B - raízes) e Açúcares não redutores (C - folhas; D raízes) em plantas jovens de Schizolobium amazonicum Huber ex Ducke acometidas à dosagens de $\mathrm{AlCl}_{3}$.
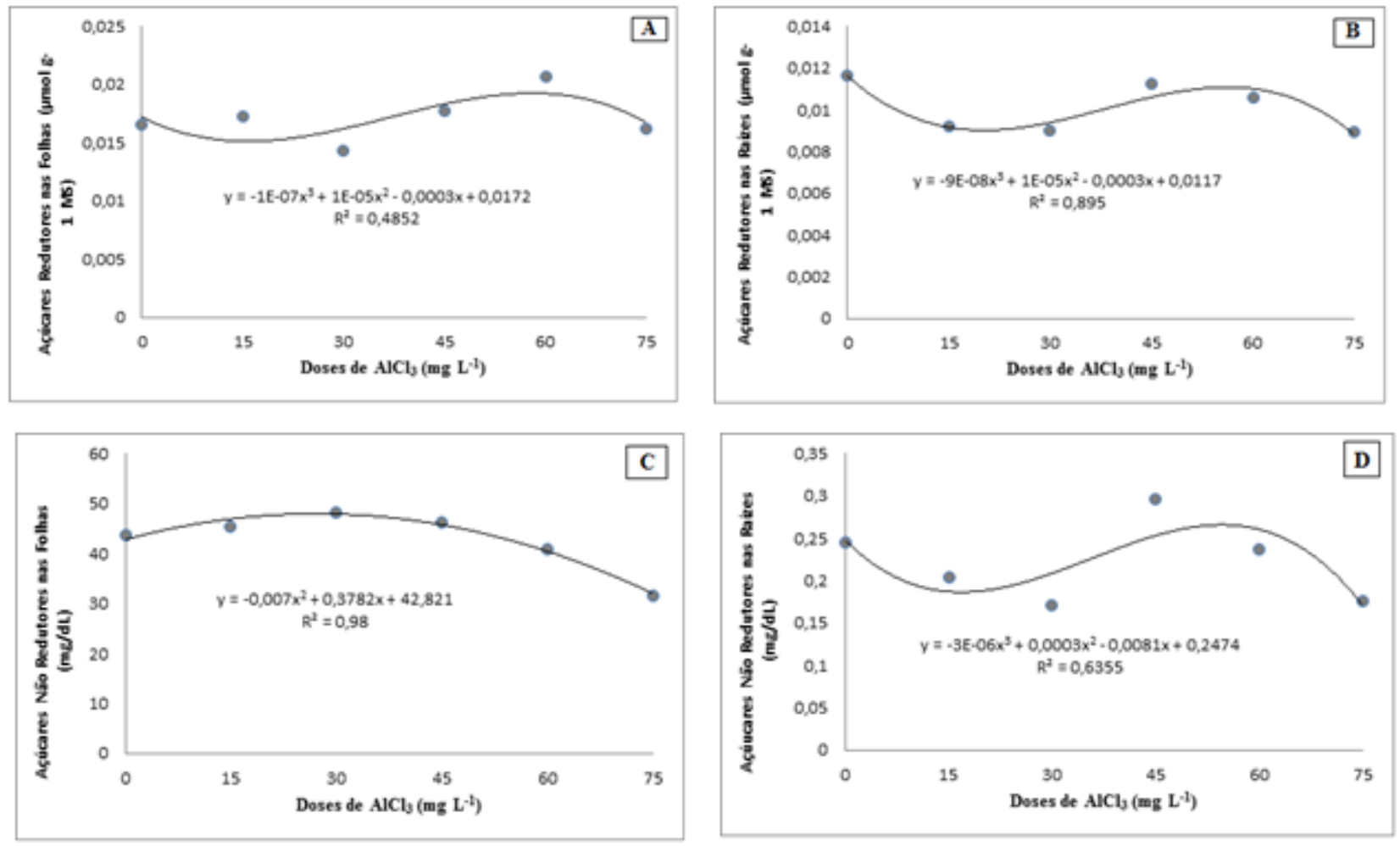

Os teores de sacarose nas folhas apresentaram aumento (83.50\%) nas concentrações a partir da dosagem de $45 \mathrm{mg} \mathrm{L}^{-1}$ (Figura 3A), e nas raízes os valores apresentados foram de $2.79 \mathrm{mg} / \mathrm{g}$ MS no tratamento controle à $3.95 \mathrm{mg} / \mathrm{g}$ MS na dosagem de $75 \mathrm{mg} \mathrm{L}^{-1}$ (Figura 3B), com $41.60 \%$ de aumento. Este comportamento deve-se à biossíntese de sacarose, e provavelmente é promovido pela maior atividade da enzima sacarose fosfato sintase (HOEKSTRA et al, 2001). 
Figura 3. Concentrações de Sacarose (E - folhas; F - raízes) em plantas jovens de Schizolobium amazonicum Huber ex Ducke acometidas à dosagens de $\mathrm{AlCl}_{3}$.
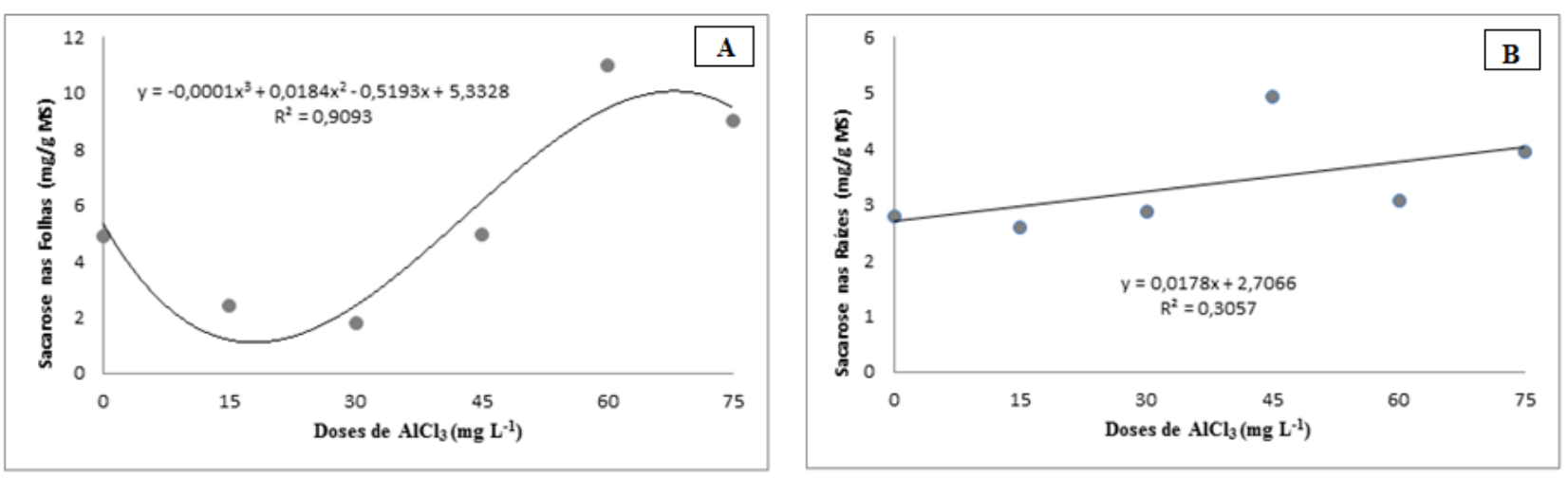

Observou-se que a dosagem de $15 \mathrm{mg} \mathrm{L}^{-1}$ promoveu nas folhas um considerável decréscimo na concentração de glicina-betaína (aprox. 50\%) com valor de $2.84 \mathrm{mg} / \mathrm{g}$ MS se comparado com a concentração no tratamento controle. (Figura 4A). O teor de glicina-betaína nas raízes mostrou valores de $7.34 \mathrm{mg} / \mathrm{g}$ MS no tratamento controle e $6.33 \mathrm{mg} / \mathrm{g}$ MS na dosagem de $75 \mathrm{mg} \mathrm{L} \mathrm{L}^{-1} \mathrm{de} \mathrm{AlCl}_{3}$, um decréscimo de $13.76 \%$ em seus teores (Figura 4B). A síntese de glicina-betaína deve-se à provável formação de aminoácidos através da degradação das proteínas, possivelmente da fotorrespiração e processos de desaminações (McNEIL; NUCCIO; HANSON, 1999).

O maior acúmulo de glicina betaína no sistema radicular (Figura 4B) sinaliza que este é o primeiro órgão afetado pelo alumínio na planta. Sendo assim, esse acúmulo ocorreu para proteger o metabolismo (MELONI, 2004).

Figura 4. Concentrações de Glicina-betaína (A - folhas; B - raízes em plantas jovens de Schizolobium amazonicum Huber ex Ducke acometidas à dosagens de $\mathrm{AlCl}_{3}$
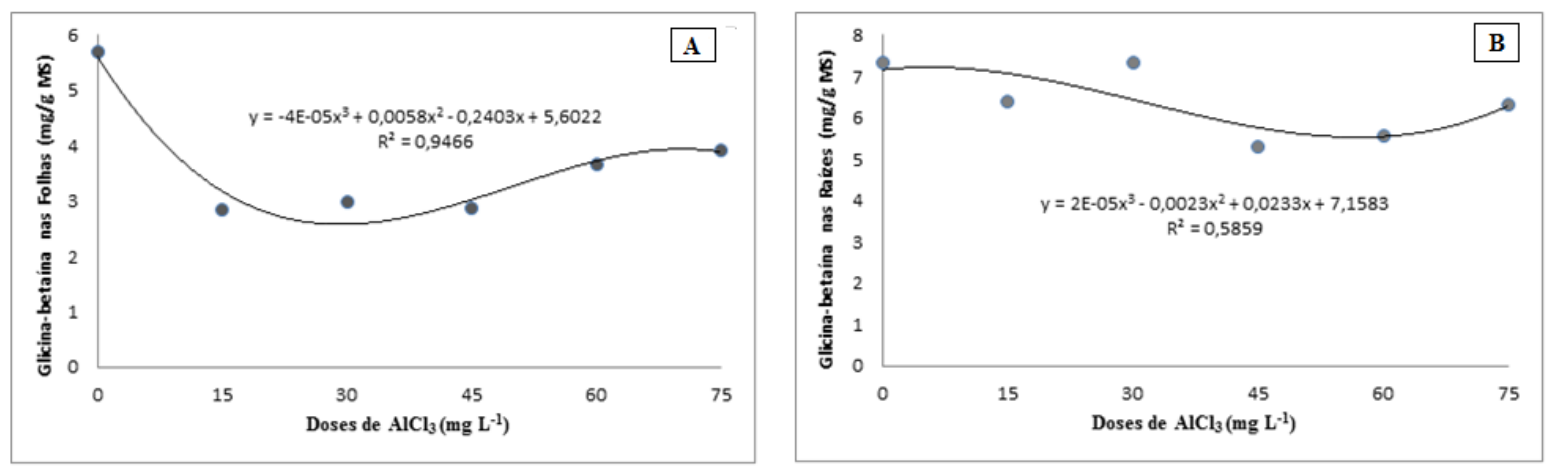

\section{Conclusões}

Verificou-se que houveram alterações consideráveis nas variáveis bioquímicas avaliadas, sobretudo quando aplicada a dosagem de $75 \mathrm{mg} \mathrm{L}^{-1}$, apresentando mecanismos de defesa que foram 
capazes de prolongar as atividades fisiológicas no tempo de exposição e nas dosagens estudadas.

\section{Referências}

DELHAIZE, E.; MA, J.F.; RYAN, P.R. Transcriptional regulation of aluminium tolerance genes. Trends in Plant Science, v. 17, p. 1360-1385, 2012.

GRIEVE, C.M., GRATTAN, S.R. Rapid assay for determination of water soluble quaternary ammonium compounds. Plant and Soil 70: 303-307, 1983.

HODGE, J. E.; HOFREITER, B. T. Determinationvof reducing sugars and carbohydrates. In:vWHISTLER, J. E.; WOLFROM, M. L. (Ed.). Methods in carbohydrate chemistry. New York:vAcademic Press. v. 1, p. 380-394, 1962.

HOEKSTRA, F.A.; GOLOVINA, E.A.; BUITINK, J. Mechanism of plant desiccation tolerance. Trends in Plant Science, Amsterdam, v. 6, n.9, p.431-438, 2001.

JONES, D.; BLANCAFLOR, E.; KOCHIAN, L.; GILROY, S. Spatial coordination of aluminium uptake, production of reactive oxygen species, callose production and Wall rigidification in maize roots. Plant Cell and Environment 29: 1309-1318, 2006.

McNEIL, S.D.; NUCCIO, M.L.; HANSON, A.D. Betaines and related osmoprotectants. Targets for metabolic engineering of stress resistance. Plant Physiology, v.120, p. 945-949, 1999.

MELONI, D.A. Braz J. Plant Physiol., 16 (1):39-46 (2004). manipulation of leaf senescence. Plant Physiology, v. 113, p. 313-319, 1997.

PAL'OVE-BALANG, P.; MISTRIK, I. Effect of aluminium on nitrogen assimilation in roots of Lotus japonicus. Plant Biosystems, Oxon, v. 145, n. 3, p. 527-531, 2011.

PIMENTEL, C. A relação da planta com a água. EDUR, Seropédica, p.191. 2004.

RINNER, K.T, SAURER, M; STREIT, K; SIEGWOLF, R.T.W. Evaluation of a liquid chromatography method for compoundspecific $\delta 13 \mathrm{C}$ analysis of plant carbohydrates in alkaline media. Rapid Commum Mass Spectrom, n. 26, p. 2173-2185, 2012.

ROSA, L.S. Características botânicas, anatômicas e tecnológicas do paricá (Schizolobium amazonicum Huberr ex Ducke). Revista de Ciências Agrárias/Amazonian Journal of Agricultural and Environmental Sciences, v. 46, n. 1, p. 63-80, 2011.

SHARMA, P.; DUBEY, R.S. Modulation of nitrate reductase activity in rice seedlings under aluminium toxicity and water stress: role of osmolytes as enzyme protectant. Journal of Plant Physiology, v.162, p.854-862, 2005.

VAN HANDEL, E. Direct microdetermination of sucrose. Analytical Biochemistry, v. 22: p. 280283, 1968. 